\title{
Repeated methylene blue administration produces analgesia in experimental pain
}

\author{
A Dondas ${ }^{1}$, A Luca', T Alexa ${ }^{1 *}$, VA Grigoras², OC Mungiu', CR Bohotin ${ }^{1}$ \\ From The European Headache and Migraine Trust International Congress \\ London, UK. 20-23 September 2012
}

\section{Introduction}

Methylene blue (MB), a widely used inhibitor of NO activity/production, is also a reduction-oxidation agent that can act both as a powerful antioxidant and as an enhancer of the electron transport chain. Furthermore, it prevents formation of mitochondrial oxygen free radicals and promotes oxygen consumption (Atamna et al. 2010,,Rojas et al. 2012).

\section{Purpose}

The aim of the study was to investigate the effects of chronic (14 days) MB administration on experimental pain in mice.

\section{Methods}

Sixteen Swiss male mice were divided into 2 groups: control group $(n=8)$ and MB group $(n=8)$; both groups received daily injections, for 14 days, either with saline 20 Î1/4l i.p. (control group) or with MB $5 \mathrm{mg} / \mathrm{kg}$ b.w. i.p (MB group). Nociceptive tests (tail flick and hot plate) as well as mechanical and thermal withdrawal thresholds were measured every two days before $\mathrm{MB} /$ saline administration. Before and two hours after the last dose was administered (day 14), each group was evaluated for the nociceptive tests and heat/mechanical hyperalgesia; results were compared with paired Student's t test. After nociceptive tests, the mice received $20 \hat{\mathrm{I}} 1 / 4 \mathrm{l}$ of $5 \%$ formalin into the upper right lip and the intensity of the orofacial pain was assessed. The results were compared with those from saline group using unpaired Student's t test.

\section{Results}

Chronic administration of $\mathrm{MB}$ increased tail flick and hot plate latencies $(\mathrm{p}=0.03, \mathrm{p}=0.02)$. We also noted an increase in the reaction time for thermal hyperalgesia assessed by Hargreaves method ( $\mathrm{p}=0.04)$. As for the formalin-induced orofacial pain, $\mathrm{MB}$ produced a significant analgesic effect on both phases $(\mathrm{p}=0.03)$.

\section{Conclusion}

Our study demonstrates that chronic administration of $\mathrm{MB}$ has analgesic effects on acute nociception as well as on the orofacial inflammatory pain; further studies must be conducted in order to elucidate the mechanism by which the methylene blue exerts its antinociceptive effect.

\section{Acknowledgements}

Research supported by Executive Agency for Higher Education and Research Funding (UEFISCSU) Romania project PN-IIID-PCE-2011-3-0875.

\section{Author details \\ ${ }^{1}$ Centre for the Study and Therapy of Pain, University of Medicine and Pharmacy, Grigore. T. Popa, Romania. ${ }^{2}$ Department of Neurology, Rehabilitation Hospital, University of Medicine and Pharmacy, Grigore. T. Popa, Romania.}

Published: 21 February 2013

\section{References}

1. Atamna H, Kumar R: Protective role of methylene blue in Alzheimer's disease via mitochondria and cytochrome coxidase. $J$ Alzheimers Dis 2010, 20:5439-52.

2. Rojas JC, Bruchey AK, Gonzalez-Lima F: Neurometabolic mechanisms for memory enhancement and neuroprotection of methylene blue. Prog Neurobiol 2012, 96:32-45.

\section{doi:10.1186/1129-2377-14-S1-P86}

Cite this article as: Dondas et al.: Repeated methylene blue administration produces analgesia in experimental pain. The Journal of Headache and Pain 2013 14(Suppl 1):P86. 